\title{
Survey and Design Consistency Evaluation in Two-Lane Rural Road Segments
}

\author{
PANAGIOTIS LEMONAKIS, GEORGE KOURKOUMPAS, \\ GEORGE KALIABETSOS, NIKOLAOS ELIOU
}

\author{
Department of Civil Engineering, Section of Transportation, University of Thessaly, \\ Pedion Areos, 38334 Volos, GREECE
}

\begin{abstract}
The present research proposes a time and cost-effective methodology to survey and perform a design consistency evaluation in two-lane rural road segments. The implementation of the proposed methodology carried out in Central Greece and more particularly along the national road Volos-Karditsa, from the local community Mikrothives up to the entrance of the Volos municipal unit. The road survey methodology, the process of creating the terrain model as well as the cross-check between the designed road with the requirements included in the Greek Road Design Guidelines Manual-Chapter X, are analytically presented. Similar checks are also performed for the sight distance throughout the road segments aiming to enable the rehabilitation of existing rural roads and enhance their safety level.

The design of the road was followed by the execution of an experiment with the participation of a motorcycle rider aiming at the recording of his trajectory throughout the road which was then compared with its geometry. The experiment carried out by exploiting an instrumented vehicle and GPS technology. Several conclusions were drawn regarding the encroachment of the centerline and the deviation from the theoretical trajectory in the middle of the travelled way. Subsequently, the proposed methodology provides a reliable and simple solution of surveying and evaluating a 2-lane rural road in safety terms.
\end{abstract}

Key-Words: - Design consistency, GPS, road safety, rural road survey.

Received: March 17, 2021. Revised: October 26, 2021. Accepted: December 19, 2021. Published: January 9, 2022.

\section{Introduction}

The primary objects of the present research were to propose a road surveying method for the assessment of road alignments on the one hand and to inspect whether an existing two-lane rural road meets certain safety criteria on the other hand. The methodology that was followed to design the terrain model is presented in detail whereas at the end of the research the proposed methodology is evaluated through a case study. The safety requirements are derived from the Greek Road Design Guidelines Manual [1] which determines the safety criteria upon which a road is evaluated. The ultimate aim of the present research is to introduce a cost and time-effective method to specify the road segments that need to be upgraded and reach an acceptable safety level.

The widespread practice of road surveying methods is the development of digital terrain models, based on known terrain coordinates in the three-axis system. These coordinates are used to generate the digital terrain model exploiting the triangulation method. The generated digital terrains can be used thereafter in many sophisticated road design software such as Anadelta Tessera (used in the present research), $\mathrm{O} \Delta \mathrm{O} \Sigma \mathrm{V} 8$, Diolkos3d, etc [2, 3].
Various attempts to develop a comprehensive methodology to evaluate the safety level of existing road segments have been documented in the past. The first step in all of them was the digital survey of the vertical and horizontal alignment of a road. The first documented attempt was by Psarianos et al in 2001 [4] who managed to survey and calculate the alignment of $1.300 \mathrm{~km}$ of the national road network in Greece. The outcome of the study was the development of the Hellas Road Software which required the use of a GPS receiver, a pc, an inclinometer, three cameras and, an instrumented light truck, and provided particularly accurate road alignments.

Another relevant study was conducted at the National Technical University of Athens in which Software H12 was developed [5]. The imported data to H12 are only the $\mathrm{x}, \mathrm{y}, \mathrm{z}$ coordinates of the axis of the road segment. Through the software, the angular and azimuth diagrams of the road are calculated which form the basis for the design of the horizontal and vertical alignment of the road. Another research that was conducted in the same University used the topographic survey method to investigate the trajectories of cars along horizontal curves [6]. Although this method offers a high degree of accuracy, it is non-cost and time-effective. 
An alternative approach to identify the alignments of existing roads used the recorded data from a GPS device throughout the borderlines of the road [7]. The geometry of each borderline individually was automatically calculated through an algorithm that was compiled on FORTRAN programming language. The efficiency of the proposed methodology was tested in two road segments with satisfactory results.

At a later stage, the aforementioned algorithm was improved by joining arcs of the same direction with small tangents in between. The outcome was the assessment of a more accurate road alignment [8]. The tests at the same road segments confirmed that the updated algorithm provides better alignments.

\section{Methodology}

The study area is located at the prefecture of Magnesia near to Volos - Greece. It has a length of approximately $17.100 \mathrm{~m}$ and belongs to the AIII type of road as defined in the Greek Road Design Guidelines Manual Chapter 1 [9]. The starting point is the end of I/C Mikrothives of the Athens - Thessaloniki motorway. The terrain up to Nea Achialos municipal is plain with smooth differences in altitude whereas on the contrary the road segment after Nea Achialos traverses a hilly terrain where multiple horizontal curves lie (Fig. 1).

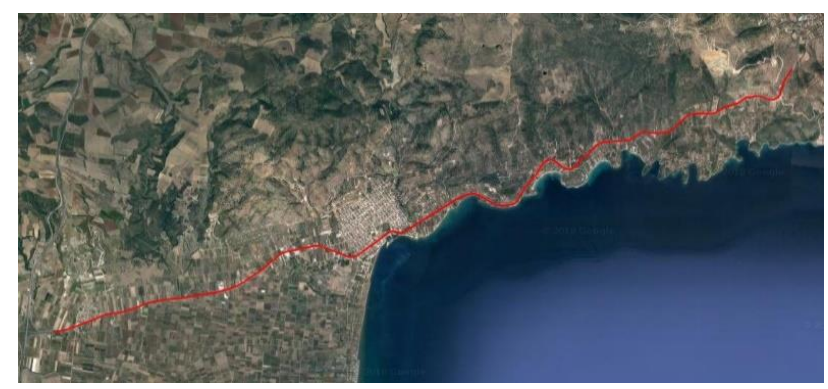

Fig. 1: Sketch of the rural 2-lane road [10]

\subsection{Surveying method}

The instrument that was used to survey the borderlines of the road segment considered was the Global Navigation Satellite System (GNSS) receiver Stonex S9 III (Fig. 2). The GNSS receiver was connected to the CivilShop networks of continuously operating reference stations [11]. The recording equipment uses the Greek Geodetic Reference System 87.

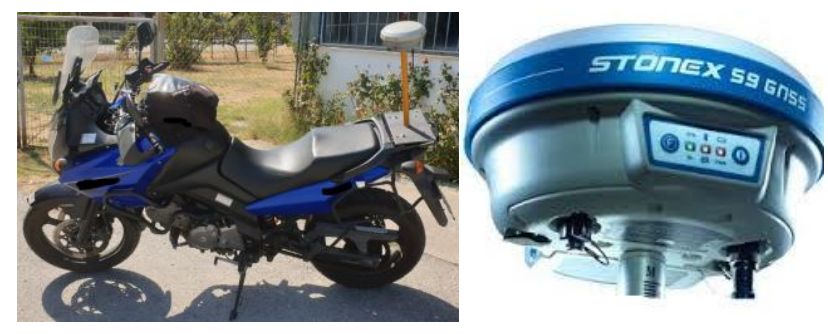

Fig. 2: Survey GPS Stonex S9 III on vehicle [10]
The accuracy of the measurements was as follows:

- Horizontal Axis x-y (plane): 0,02 m.

- Vertical Axis z (elevation from sea level): 0,05 m.

- Recording rate: $1 \mathrm{~Hz}$.

The trajectory of the instrumented vehicle was as close as possible to the right borderline whereas throughout the operation its speed was less than $20 \mathrm{~km} / \mathrm{h}$. These settings combined with the geometric features of the road segment resulted in 5.069 recorded points for both borderlines of the road.

\subsection{Generation of the Terrain Model}

The first step to generate the terrain model was to import the recorded data (ground profile data) from the GNSS receiver into software Anadelta Tessera which automatically generates a terrain model from the raw data. A preview of the imported data is presented on Fig. 3 (a) whereas on Fig. 3 (b) a series of recorded points on a random segment for both borderlines is depicted.

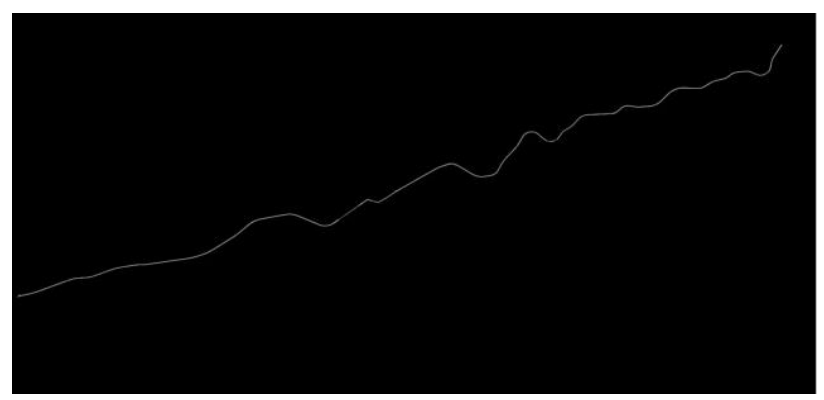

(a)

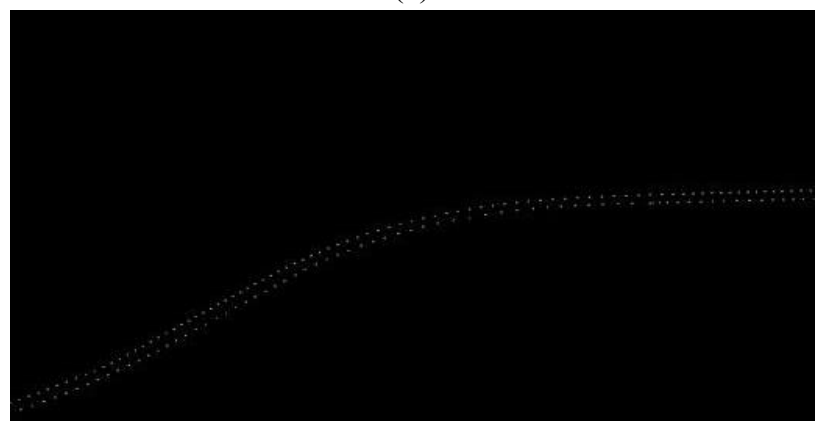

(b)

Fig. 3: Import of borderlines points [10]

A more detailed examination of Fig. 3 revealed inconsistencies on the recorded data either due to temporary loss of signal between the GNSS and GPS or due to various obstacles that were lying on the right side of the pavement rendering the movement of the instrumented vehicle above them impossible (e.g. parked cars, trash bins). Attempting to overcome this finding, an approximate calculation of the terrain points at the inconsistent segments performed aiming to achieve a better illustration of both the horizontal alignment as well as to the terrain model. More precisely, various points were imported throughout the inconsistent segments. The altitude of these points was calculated by implementing 
linear interpolation between the points that were preceding and following the new ones. At the next stage, all points are joined to form a united database, and finally, the triangulation method implemented.

With this procedure the terrain model of the existing road developed, which was then used as the fundamental element to proceed to the design of the road alignment. The similar procedure implemented to calculate a second terrain model along to the study area using terrain points from Google Earth. The latter model permitted the illustration of the terrain beyond the borderlines of the road.

\subsection{Road Design}

The terrain model as calculated by the terrain points that were recorded with the GNSS receiver was used to design the alignment of the road. That was accomplished by a supervised/graphical method through an appropriate software (Anadelta Tessera) by taking the borderlines of the road as granted. The result was the design of the axis of the road segment as a sequence of joined straight lines and arcs (Fig. 4).

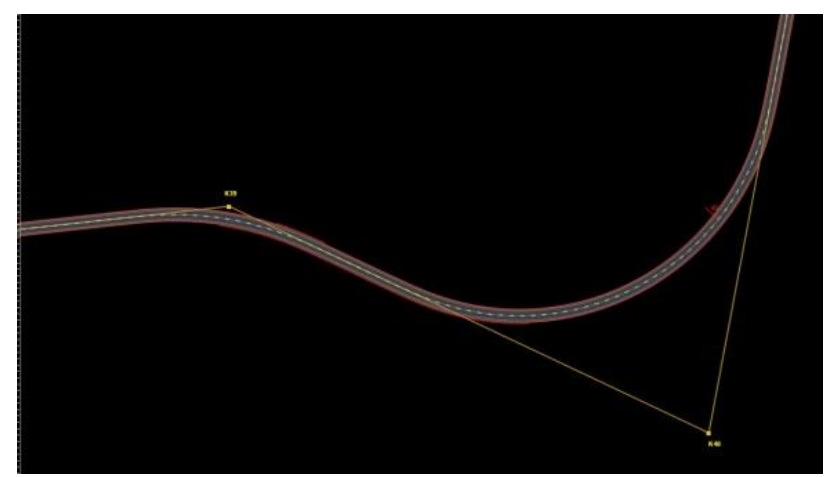

Fig. 4: Original road alignment [10]

The ultimate stage of the horizontal design of the road was to insert the clothoids at the beginning and end of each horizontal curve. That was also accomplished with a similar supervised/graphical method by adjusting the value of parameter A of the clothoid to fit the terrain model (Fig. $5)$.

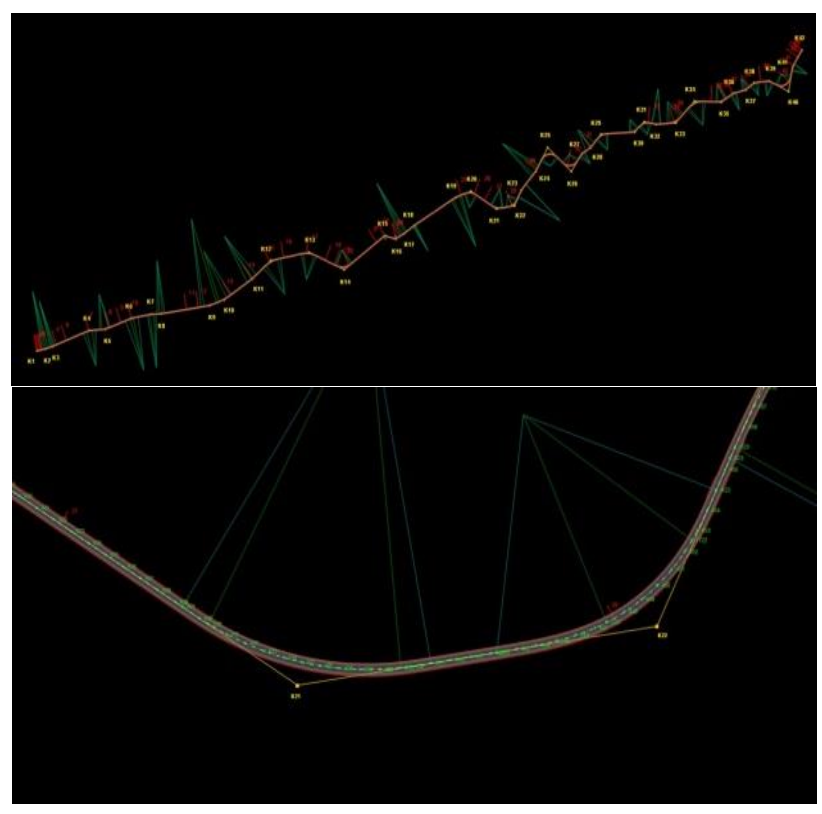

Fig. 5: Final road alignment [10]

The terrain model together with the horizontal alignment were the two prerequisites to design the vertical alignment, the cross-section, and the superelevation diagram of the road (Fig. 6). That was performed through the design software which offers the possibility to automatically generate the vertical alignment of the surveyed road segment, once the horizontal alignment has been finalized. The vertical alignment and the crosssections are also automatically regenerated after any changes occur to the horizontal alignment.

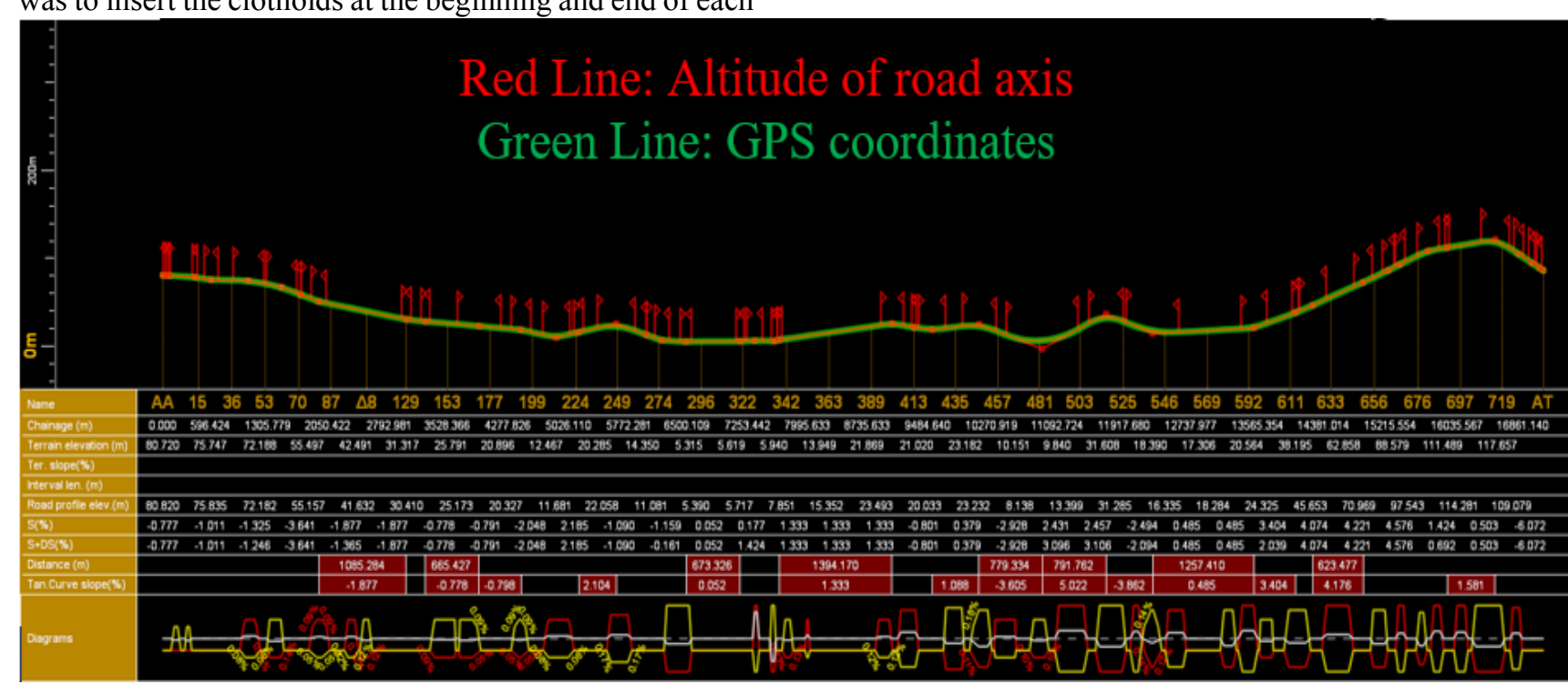

Fig. 6: Vertical alignment - Axis of GPS points [10] 
The design of the longitudinal profile was also performed with the implementation of the supervised/graphical method. Particular attention was given to ensure that the road centreline vertical alignment along tangents was approximately $+0.10 \mathrm{~m}$ above the ground vertical alignment derived from the recorded ground profile data. This limit was set because the recorded ground profile data refer to the borderline instead of the axis of the road. Therefore, it was deemed that in the tangent segments the difference between the centreline and both borderlines of the road was approximately $+0.10 \mathrm{~m}$. On the contrary along the curves, efforts were put to ensure that the elevation of the centreline and the elevation of the ground digital elevation model were identical.

\section{Results}

\subsection{Safety criteria}

The next step of the research was the evaluation of the road segment from the first two safety criteria determined in the Greek Road Design Guidelines Manual-Chapter X [1] i.e. design consistency according to the design speed and design consistency according to the operational speed $\mathrm{V}_{85}$. The original design of the road was not available and hence the value of the design speed, a necessary component to evaluate the first safety criteria, was not known. To overcome this shortcoming, the design speed was set as the mean value of the operational speed $\mathrm{V}_{85}$. It must be noted that the various operating speeds were calculated automatically using suitable software and therefore the calculation of their mean speed was effortless. More specifically the mean value of the operational speed was $87 \mathrm{~km} / \mathrm{h}$ and hence the design speed $\mathrm{V}_{\mathrm{e}}$ was approximately chosen equal to $80 \mathrm{~km} / \mathrm{h}$. The calculation of the difference $\left|\mathrm{V}_{85}-\mathrm{V}_{\mathrm{e}}\right|$ for the consecutive road segments was then feasible.

According to the first safety criterion the design of an existing road is classified according to the following conditions, depending on the value of the afore-mentioned difference:

- less than $10 \mathrm{~km} / \mathrm{h}$ "good"

- between $10 \mathrm{~km} / \mathrm{h}$ and $20 \mathrm{~km} / \mathrm{h}$ "moderate"

- more than $20 \mathrm{~km} / \mathrm{h}$ "poor" (redesign is mandatory)

In this way, the road segments were sorted based on the value of the corresponding $\mathrm{V}_{85}$. The implementation of the first criterion to the road under investigation disclosed that its design consistency is rather "moderate".

Taking the operational speeds of the road as granted the next step was to implement the second safety criterion which compares the differences $\left|V_{85 i}-V_{85 i+1}\right|$, between the consecutive road elements. A road element is either a straight line (tangent) or a curve section of the form entry clothoid-circular curve- exit clothoid. The conditions that should be met to decide whether two consecutive road elements are considered optimum, moderate, or not acceptable are similar to the first criterion. According to the second criterion and by considering the individual scores between the consecutive road elements the road under investigation is classified as "good".

\subsection{Sight distance}

To enhance traffic safety as well as the quality of the traffic flow, minimum sight distances must be ensured. From this perspective the road users will be alerted on time for potential threats on the pavement (stopping sight distance), an adequate distance for overtaking will be available (sight distance for overtaking) and the drivers can exploit more time to change their trajectory if needed (sight distance for decision making).

Through the design software the sight distance for specific road segments that met certain requirements e.g. sharp horizontal curves combined with convex crest curve, was calculated (Fig. 7).

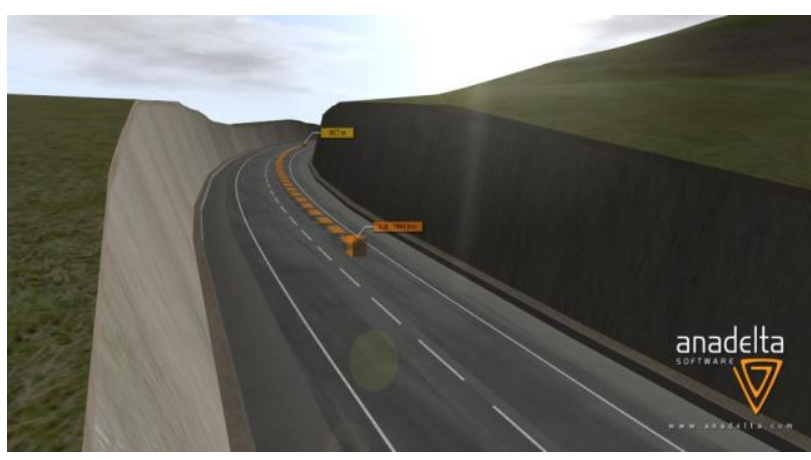

Fig. 7: Example of sight distance [10]

The data to accomplish this task was obtained from Google Earth [12]. Initially, the paths that circumscribe the road under investigation were plotted (Fig. 8) by joining the scattered 2-dimensional points. Subsequently, in each one of the plotted points, an altitude was assigned through the online project GPS Visualizer which derives altitude data from NASA's database [13].

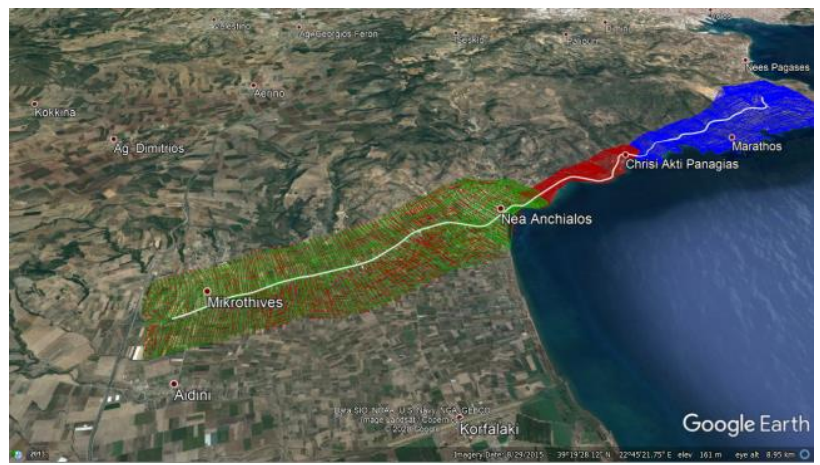

Fig. 8: Generation of path points [10]

This new model constituted the basis on which the road that was produced at the first stage merged. As presented in Table 1 the road designed with the procedure described before is particularly accurate. 
Table 1: Average - Mean deviation - Mean standard deviation

\begin{tabular}{cccc}
\hline \hline & $\begin{array}{c}\text { Average } \\
\text { altitude } \\
\text { difference (Axis } \\
\text { altitude } \\
\text { ANADELTA- } \\
\text { Axis altitude } \\
\text { GPS) }\end{array}$ & $\begin{array}{c}\text { Mean } \\
\text { deviation } \\
\text { (Altitude } \\
\text { difference - } \\
\text { Average) }\end{array}$ & $\begin{array}{c}\text { The standard } \\
\text { deviation of } \\
\text { altitude } \\
\text { difference } \\
\text { (Axis altitude } \\
\text { ANADELTA- } \\
\text { Axis altitude } \\
\text { GPS) }\end{array}$ \\
\hline $\begin{array}{c}\text { Mikrothives - } \\
\text { Volos } \\
\text { Mikrothives - } \\
\text { Anchialos }\end{array}$ & 0.0165 & 0.0709 & 0.0894 \\
Anchialos - \\
Volos
\end{tabular}

On the contrary, the terrain model did not accord with reality. Altitude deviations of 2-3 meters were identified which is considered as an acceptable error.

\section{Conclusions}

The subject of the present research was, on the one hand, the introduction of a reliable and practical methodology of surveying an existing road whereas on the other hand the evaluation of the road geometry according to the first two criteria mentioned in the Greek Road Design Guidelines Manual-Chapter $\mathrm{X}$ and to the adequacy of sight distance. The procedure that has been implemented so far to survey and evaluate the road segments in safety terms is time and cost consuming since it requires the use of specialized equipment and sophisticated software. Moreover, the use of GPS technology to calculate the boundary lines of the various road sections lacks accuracy since the GPS only offers a $3 \mathrm{~m}$ position accuracy. Therefore, it provides horizontal and vertical alignments which do not imprint the actual road. On the other hand, the proposed methodology is not only cost but also time effective because it utilizes freeware software and a relatively inexpensive device. These benefits renders it an ideal solution for both professional and educational purposes.

The next steps might include the evaluation of the road based on the requirements of the German (RAA) [14] or the American Guidelines [15]. Therefore, the methodology described before provides a reliable, easy, and costeffective tool to survey and evaluate not only existing road segments but also preliminary road designs.

\section{References}

[1] Ministry of Environment Regional Plannin $\mathrm{g}$ and Public Projects, Guidelines for the Design of Road Infrastructure Projects Designs, Chapter 3: General Secretariat of Public Works, 2001.

[2] Anadelta Tessera, "http://www.anadelta.com/indexgr.php?s=tessera," [Online].
[3] Diolkos3d, "https://www.diolkos3d.com/," [Online].

[4] B. Psarianos, D. Paradisis, B. Nakos and G. Karras, "A cost-effective road surveying method for the assessment of road alignments," in IV International Symposium Turkish-German Joint Geodetic Days, Berlin, 2001.

[5] Vasilas, Development of an algorithm to digitaly design an existing road, Athens, Greece: National Technical University of Athens, Thesis, 2013.

[6] E. Siora, Investigation of the real curvature of the vehicle's trajectory concerning the design curvature of two-lane rural roads, Athens, Greece: National Technical University of Athens, Thesis, 2009.

[7] N. Eliou, G. Kaliabetsos, G. Karaoglanis and A. Galanis, "Development of and algorith to identify the geometry of an existing road," in $6 \mathrm{~h}$ Panhellenic Conference on Road Safety, Athens, 2015.

[8] Papadopoulos, Algorithm to identify the geometry of an existing road, Volos, Greece: University of Thessaly, Thesis, 2017.

[9] Ministry of Environment Regional Planning and Public Projects, Guidelines for the Design of Road Infrastructure Projects Operational Classification of Road Network, Chapter 1: General Secretariat of Public Works, 2001.

[10] G. Kourkoubas, Survey and check of the geometrical features of an existing road, Volos, Greece: University of Thessaly, Thesis, 2018.

[11] CivilShop, "http://www.civilshop.gr/," [Online].

[12] Google Earth, "https://www.google.com/earth/," [Online].

[13] S. T. NASA, "https://www2.jpl.nasa.gov/srtm/," [Online].

[14] M. Rohloff, Richtlinien für die Anlage von Autobahnen (Guidelines for the design of motorways), FGSV, R1, Regelwerk., 202: Köln : FGSV-Verl., 2008.

[15] AASHTO, Policy on Geometric Design of Highways and Streets, 6th Edition: American Association of State Highway and Transportation Officials, 2011. 


\section{Contribution of individual authors to the creation of a scientific article (ghostwriting policy)}

Panagiotis Lemonakis contributed to all steps of the present study and particularly he organized, executed and, analyzed the field measurements.

George Kourkoumpas was responsible for the set up of the field measurements and the post statistical analysis.

George Kaliabetsos contributed to the literature review of the study and the post analysis of the recorded data.

Nikolaos Eliou assisted in the recruitment and execution of the field measurements presented in section 2.1 and the interpretation of the results.

\section{Sources of funding for research} presented in a scientific article or scientific article itself

This research study was conducted under the postdoc scholarship supported by the University of Thessaly and exclusively funded by Stavros Niarchos Foundation.

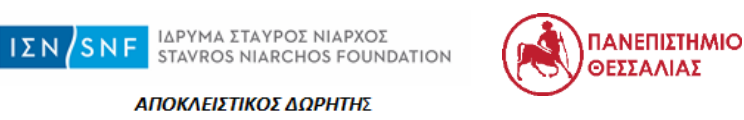

\section{Creative Commons Attribution}

\section{License 4.0 (Attribution 4.0}

\section{International, CC BY 4.0)}

This article is published under the terms of the Creative Commons Attribution License 4.0 https://creativecommons.org/licenses/by/4.0/deed.en US 